\title{
Synthesis and Characterization of Cr Doped ZnO Nanocrystals
}

\author{
Vishwanath Dattu Mote, Vishnu Ramrao Huse, Babasaheb Nivrutti Dole* \\ Advanced Materials Research Laboratory, Department of Physics, Dr. Babasaheb Ambedkar Marathwada University, Aurangabad, \\ India. \\ Email: *drbndole.phy@gmail.com
}

Received June $7^{\text {th }}, 2012$; revised July $6^{\text {th }}, 2012$; accepted July $18^{\text {th }}, 2012$

\begin{abstract}
Samples of chromium doped $\mathrm{ZnO}$ were synthesized using co-precipitation technique at room temperature. Structural and optical properties of $\mathrm{Cr}$ doped $\mathrm{ZnO}$ samples were investigated by X-ray diffraction technique (XRD and UV-Visible spectroscopy (UV-Vis) respectively. X-ray diffraction (XRD) patterns confirm that the samples have hexagonal (wurtzite) structure with no additional peak which suggests that $\mathrm{Cr}$ ions go to the regular $\mathrm{Zn}$ sites in the $\mathrm{ZnO}$ crystal structure. The lattice constants were calculated using X-ray diffraction data and it is found that lattice parameters decrease with increasing $\mathrm{Cr}$ content. The average grain size was calculated using Scherrer's formula for pure and $\mathrm{Cr}$ doped $\mathrm{ZnO}$ samples and it is observed that grain size is in the range 11 to $17 \mathrm{~nm}$. Band gap of $\mathrm{Zn}_{1-\mathrm{x}} \mathrm{Cr}_{\mathrm{x}} \mathrm{O}$ samples has been evaluated using UV-Vis spectrometer. It is found that the band gap decreases as $\mathrm{Cr}$ increases; it is attributed to the $\mathrm{s}-\mathrm{d}$ and $\mathrm{p}$ interactions and the smaller average grain size. It indicates that incorporation of $\mathrm{Cr}$ ions into the $\mathrm{ZnO}$ matrix. The chemical species of the grown crystals were identified by Fourier transform infrared spectroscopy (FTIR). From FTIR spectra it is observed that IR peaks corresponding to the Zn-O bands. Such results are presented in this paper quantitatively and qualitatively.
\end{abstract}

Keywords: Wurtzite Structure; Average Grain Size; Scherrer’s Formula; FTIR Spectra

\section{Introduction}

In recent years, much attention has been paid to Diluted Magnetic Semiconductors (DMSs) formed by the partial replacement of cations in a non-magnetic semiconductor by magnetic transition metal ions for spintronic applications. Spintronics is a field which investigates the applications of carrier spins transport as well as charge transport in a new generation of devices such as spin-valve transistors [1], spin light-emitting diodes [2] and logic devices [3]. To realize these devices it is necessary to develop semiconducting materials that show ferromagnetic behavior at room temperature. Among the different types of wide-band-gap semiconductors $\mathrm{ZnO}$, with a direct band gap of $3.37 \mathrm{eV}$ and a large exciton binding energy of $60 \mathrm{meV}$, has become one of the most important functional semiconducting materials for electro-optical devices like UV light emitters [4], piezoelectric transducers [5] and gas sensors [6]. Since then, many systems of TM-doped $\mathrm{ZnO}$ ( $\mathrm{TM}=\mathrm{Co}, \mathrm{Mn}, \mathrm{Ni}$, etc.) have been studied by different methods [7-10]. However, the reported experimental results on the studies of $\mathrm{Cr}$-doped $\mathrm{ZnO}$ have been very conflicting. Some studies reveal that

${ }^{*}$ Corresponding author. the magnetic behavior of $\mathrm{Cr}$-doped $\mathrm{ZnO}$ appears to be very sensitive to the deposition method. For example, Ueda et al. [11] did not observe any ferromagnetic behavior for $\mathrm{Cr}$-doped $\mathrm{ZnO}$ film grown by pulse laser deposition, whereas Roberts et al. [12] prepared $\mathrm{Cr}$ doped $\mathrm{ZnO}$ via magnetron sputtering and obtained ferromagnetic ordering at 9.5 at $\%$ doping concentration. Furthermore, the results of Jin et al. [13] showed no ferromagnetic behavior for $\mathrm{Cr}$-doped $\mathrm{ZnO}$ film at low temperatures even down to $3 \mathrm{~K}$. Lee et al. [14] did not find ferromagnetism in solgel synthesized $\mathrm{Zn}_{1-\mathrm{x}} \mathrm{Cr}_{\mathrm{x}} \mathrm{O}$ thin films; however, ferromagnetism appeared when the same films were co-doped with Li. We report a detail study on the structural and optical properties of $\mathrm{Zn}_{1-\mathrm{x}} \mathrm{Cr}_{\mathrm{x}} \mathrm{O}$ nanocrystals synthesized by co-precipitation technique at room temperature.

\section{Experimental}

\subsection{Sample Preparation}

Samples with compositional formula of $\mathrm{Zn}_{1-\mathrm{x}} \mathrm{Cr}_{\mathrm{x}} \mathrm{O}$, with $\mathrm{x}=0.00$ and 0.10 were prepared by co-precipitation route in an alcoholic medium (methanol). In this procedure, to prepare pure $\mathrm{ZnO}$, Zinc acetate dihydrate (with $99+\%$ 
purity, kemphasol make, A. R. Grade) was dissolved in methanol (100 ml) and KOH (purity 99+\%, sd FiNECHEM Limited make, A. R. Grade) was dissolved in methanol $(100 \mathrm{ml})$. Both the solutions were mixed by constant magnetic stirring by heating at $52^{\circ} \mathrm{C}$ for $2 \mathrm{~h}$. The precipitate separated from the solution by filtration, washed several times with distilled water and ethanol then dried in air at $127^{\circ} \mathrm{C}$ to obtain $\mathrm{ZnO}$ nanocrystals. For the synthesis of $\mathrm{Cr}$ doped $\mathrm{ZnO}$ nanocrystals, Zinc acetate dihydrate and Chromium acetate tetrahydrate (with $99 \%$ purity, kemphasol make, A. R. Grade) were dissolved in methanol $(100 \mathrm{ml})$ and $\mathrm{KOH}$ was dissolved in methanol $(100 \mathrm{ml})$. Both the solutions were mixed by constant magnetic stirring by heating at $52^{\circ} \mathrm{C}$ for $2 \mathrm{~h}$. The precipitate separated from the solution by filtration, washed several times with distilled water and ethanol then dried in air at $127^{\circ} \mathrm{C}$ to obtain $\mathrm{Cr}$ doped $\mathrm{ZnO}$ nanocrystals.

\subsection{Characterization}

The crystalline structure, phase purity and size of the nanoparticles were determined by X-ray diffraction (XRD) using X-ray diffractometer (Model: PW-3710) employing $\mathrm{CuK} \alpha$ radiation. Fourier Transform Infrared (FTIR) spectra of the samples were recorded using JASCO FI-IR 460 spectrometer in the range $400-4000 \mathrm{~cm}^{-1}$ by $\mathrm{KBr}$ pellet technique. Absorption spectra of the samples in the UV-visible spectral region were recorded using UVVIS-NIR (JASCO V 570) spectrophotometer.

\section{Results and Discussion}

\subsection{X-ray Diffraction Study}

Figure 1 shows XRD patterns with distinct diffraction peaks, corresponded to the (100), (002), (101), (102), (110), (103), (200), (112) and (201) lattice planes, reveal that as prepared nanocrystals have a wurtzite (hexagonal) structure. It is seen from the XRD patterns that the peaks of $\mathrm{ZnO}$ shift towards higher angles with increasing $\mathrm{Cr}$ concentration of $\mathrm{ZnO}$ samples. Such shifts of the XRD peaks reveal a lattice expansion due to the $\mathrm{Cr}$ substitution for $\mathrm{Zn}$ in the $\mathrm{ZnO}$ crystal lattice. It shows the small reduction in the lattice constant as $\mathrm{Cr}$ concentration increases. Table 1 shows the lattice constant of $\mathrm{Cr}$ doped $\mathrm{ZnO}$ was slightly decreased with increasing $\mathrm{Cr}$ concentration. It may be due to the larger ionic radius of $\mathrm{Zn}$ as compared to $\mathrm{Cr}$ ions. The volume of the unit cell was also decreased with increasing $\mathrm{Cr}$ concentration. It indicates that $\mathrm{Cr}$ ions go to $\mathrm{Zn}$ site in $\mathrm{ZnO}$ structure.

The broadening of XRD peaks attributed nano-sized formation of $\mathrm{Cr}$ doped $\mathrm{ZnO}$ samples. The average grain size of $\mathrm{Cr}$ doped $\mathrm{ZnO}$ nanocrystals are estimated using Debye Scherer's formula. It is found that the average grain size is in the range of $11-17 \mathrm{~nm}$. The average

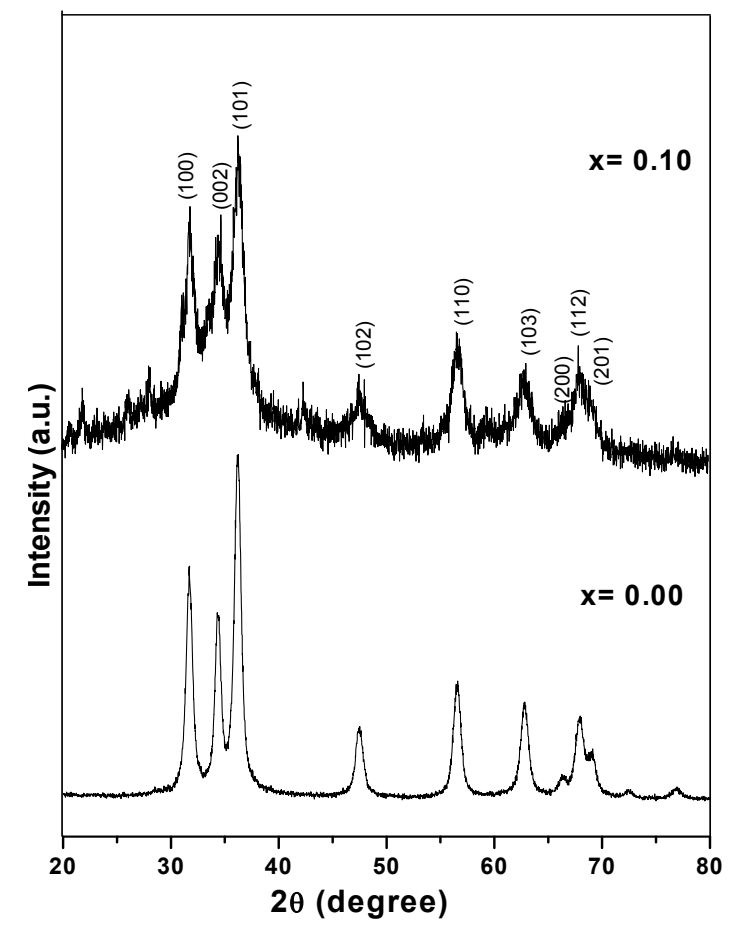

Figure 1. X-ray diffraction patterns of $\mathrm{Cr}$ doped $\mathrm{ZnO}$ at room temperature.

Table 1. Lattice parameters, grain size, volume cell and band gap at room temperature for $\mathrm{Zn}_{1-\mathrm{x}} \mathrm{Cr}_{\mathrm{x}} \mathrm{O}$ system.

\begin{tabular}{cccccc}
\hline Sample & $\mathbf{a}(\AA)$ & $\mathbf{c}(\AA)$ & $\begin{array}{c}\text { Grain } \\
\text { size }(\mathbf{n m})\end{array}$ & $\begin{array}{c}\text { Volume } \\
(\AA)^{3}\end{array}$ & $\begin{array}{c}\text { Band } \\
\text { gap (eV) }\end{array}$ \\
\hline 0.00 & 3.2606 & 5.2186 & 16.70 & 48.0494 & 3.06 \\
0.10 & 3.2406 & 5.2068 & 11.09 & 47.3555 & 2.50 \\
\hline
\end{tabular}

grain size, lattice parameter and absence of impurity phases with increasing $\mathrm{Cr}$ concentration for all samples could be attributed to the ionic radii of $\mathrm{Zn}$ and $\mathrm{Cr}$ ions. This is mainly because of the nucleation and subsequent growth rate with increasing $\mathrm{Cr}$ due to the difference of ionic radii of $\mathrm{Zn}$ and $\mathrm{Cr}$ ions.

\subsection{Fourier Transform Infrared (FTIR) Analysis}

FTIR spectra of pure and $\mathrm{Cr}$ doped $\mathrm{ZnO}$ nanoparticles are shown in the Figure 2. The broad peak in higher energy in the region at $3400-3600 \mathrm{~cm}^{-1}$ is due to $\mathrm{OH}$ stretching or it may be due to the M-OH-M. The peak in the range $1400-1757 \mathrm{~cm}^{-1}$ is due to $\mathrm{OH}$ bending of adsorbed moisture in the sample and all other peaks are attributed to the characteristic of the material. The bands appeared near at $2000-2200 \mathrm{~cm}^{-1}$ indicates the $\mathrm{CO}$ adsorption on the surface of oxide. Similarly the bands at $780-980 \mathrm{~cm}^{-1}$ might be due to the peroxide formation (M-O-O-M) and peak in the range of $900-1200 \mathrm{~cm}^{-1}$ is 


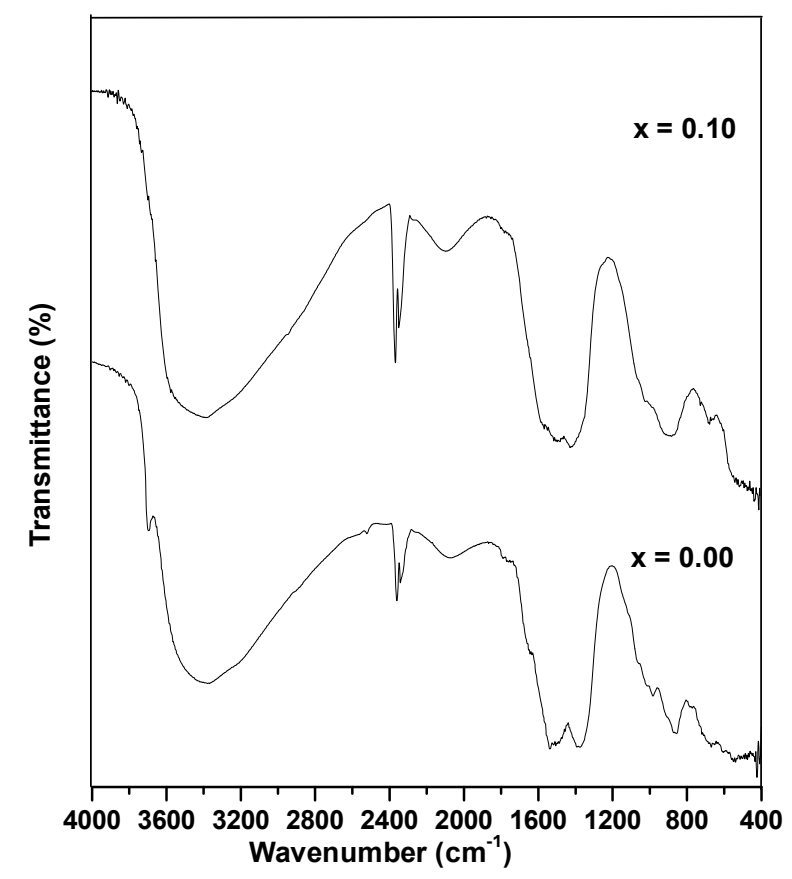

Figure 2. FTIR spectra of $\mathrm{Zn}_{1-\mathrm{x}} \mathrm{Cr}_{\mathrm{x}} \mathrm{O}$ samples.

due to the M-O-M bonding. The FTIR spectrum of the main absorption band is due to $\mathrm{Zn}-\mathrm{O}$ stretching of $\mathrm{ZnO}$ in the range of $600-400 \mathrm{~cm}^{-1}$. FTIR spectra of pure sample of the present investigation are similar to that of $\mathrm{Cr}$ doped $\mathrm{ZnO}$ samples and are in good agreement with the reported values [15-19].

\subsection{Optical Absorption and Optical Band Gap}

The room temperature UV-Vis spectra of undoped and $\mathrm{Cr}$ doped $\mathrm{ZnO}$ samples are shown in Figure 3. The maximum absorption for all samples is observed, which indicates red shift from the bulk $\mathrm{ZnO}$ samples. This red shift absorption edge is due to the small size of the particles. The band gap was calculated by plotting the- absorption plot (Energy, E) versus $(\alpha \mathrm{h} v)^{2}$. It is found that the band gaps of $\mathrm{Cr}$ doped $\mathrm{ZnO}$ samples are 2.50 - 3.06 $\mathrm{eV}$. Figure 4 shows the $\alpha$-absorption is shifted slightly towards low energy as $\mathrm{Cr}$ content increases. The band gap is found to decrease with increasing $\mathrm{Cr}$ concentration. These values are tabulated in Table 1. The decrement in $\mathrm{E}_{\mathrm{g}}$ with increasing $\mathrm{Cr}$ content is attributed to the s-d and $\mathrm{p}$ interactions and smaller average grain size.

\section{Conclusion}

Chromium doped $\mathrm{ZnO}$ nanocrystals were synthesized by co-precipitation method. Lattice parameters were determined using X-ray diffraction data and it is found that they show the wurtzite structure. The volume of unit cell decreases with increasing $\mathrm{Cr}$ concentration, it may be due to the smaller ionic radius of $\mathrm{Cr}$ ions as compared to $\mathrm{Zn}$

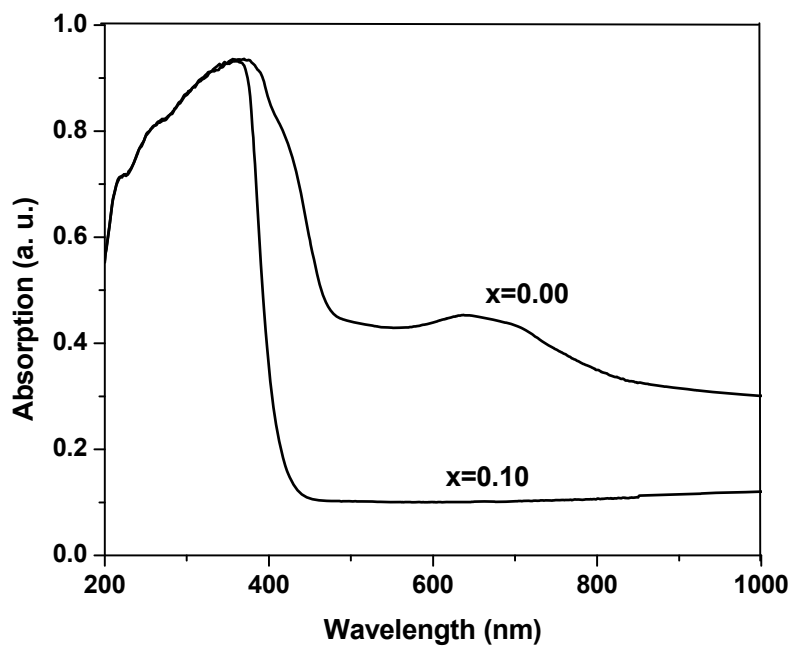

Figure 3. Absorption vs wavelength of $\mathrm{Zn}_{1-\mathrm{x}} \mathrm{Cr}_{\mathrm{x}} \mathrm{O}$ samples.

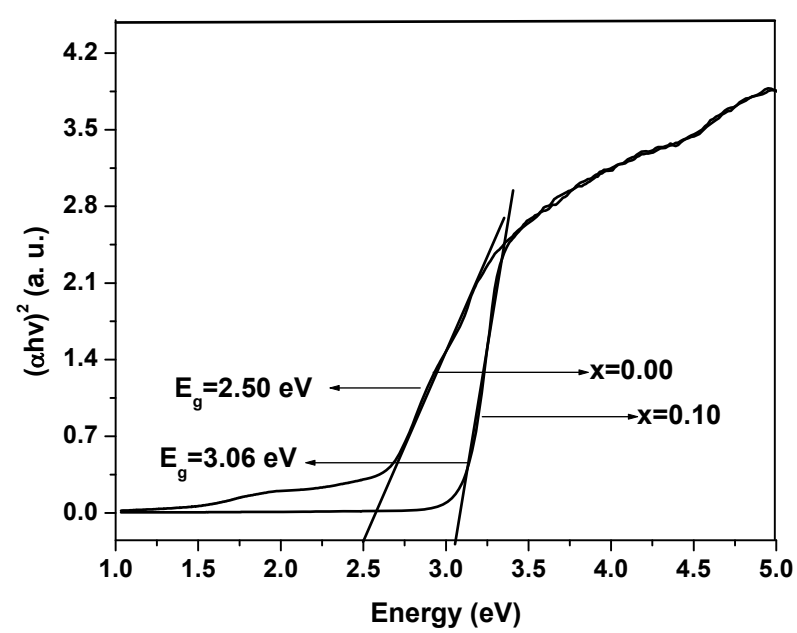

Figure 4. Energy vs $(\alpha h v)^{2}$ of $\mathrm{Zn}_{1-\mathrm{x}} \mathrm{Cr}_{\mathrm{x}} \mathrm{O}$ samples.

ions. The grain size was calculated using Scherrer's formula. It is found that the average grain size is in the range $11-17 \mathrm{~nm}$. The chemical groups of the samples have been identified by FTIR spectra. The absorption peak is shifted towards low energy side as $\mathrm{Cr}$ content increases. It may be owing to the $s-d$ and $p$ interactions and smaller average grain size of $\mathrm{Cr}$ doped $\mathrm{ZnO}$ samples.

\section{Acknowledgements}

Authors would like to thank Dr. Mahavir Singh, Professor, Department of Physics, H. P. University, Shimla (H. P.) for providing facilities, Dr. S. S. Shah for his encouragement and University Grants Commission, New Delhi for financial support through project F-37-563/2009/SR.

\section{REFERENCES}

[1] M. Tanaka and Y. Higo, "Large Tunneling Magnetoresistance in GaMnAs/AlAs/GaMnAs Ferromagnetic Semi- 
conductor Tunnel Junctions," Physical Review Letters, Vol. 87, No. 2, 2001, pp. 26602-26606. doi:10.1103/PhysRevLett.87.026602

[2] S. J. Pearton, C. R. Abernathy, M. E. Overberg, G. T. Thaler, D. P. Norton, N. Theodoropoulou, A. F. Hebard, Y. D. Park, F. Ren, J. Kim and L. A. Boatner, "Wide Band Gap Ferromagnetic Semiconductors and Oxides," Journal of Applied Physics, Vol. 93, No. 1, 2003, pp. 1-13. doi:10.1063/1.1517164

[3] Y. Z. Wang, H. Liu, Z. Q. Li, X. X. Zhang, R. K. Zheng and S. P. Ringer, "Role of Structural Defects on Ferromagnetism in Amorphous Cr-Doped $\mathrm{TiO}_{2}$ Films," $A p$ plied Physics Letters, Vol. 89, No. 4, 2006, Article ID: 042511. doi:10.1063/1.2240139

[4] W. Z. Xu, Z. Z. Ye, Y. J. Zeng, L. P. Zhu, B. H. Zhao, L. Jiang, J. G. Lu, H. P. He and S. B. Zhang, "ZnO LightEmitting Diode Grown by Plasma-Assisted Metal Organic Chemical Vapor Deposition," Applied Physics Letters, Vol. 88, No. 17, 2006, pp. 173506-173509. doi:10.1063/1.2199588

[5] Z. C. Tu and X. Hu, "Elasticity and Piezoelectricity of Zinc Oxide Crystals, Single Layers, and Possible Single-Walled Nanotubes," Physical Review B, Vol. 74, No. 3, 2006, Article ID: 035434. doi:10.1103/PhysRevB.74.035434

[6] P. Mitra, A. P. Chatterjee and H. S. Maiti, "ZnO Thin Film Sensor," Materials Letters, Vol. 35, No. 1-2, 1998, pp. 33-38. doi:10.1016/S0167-577X(97)00215-2

[7] G. Lawes, A. S. Risbud, A. P. Ramirez and R. Seshadri, "Absence of Ferromagnetism in Co and Mn Substituted Polycrystalline ZnO," Physical Review B, Vol. 71, No. 4, 2005, Article ID: 045201. doi:10.1103/PhysRevB.71.045201

[8] A. S. Risbud, N. A. Spaldin, Z. Q. Chen, S. Stemmer and R. Seshadri, "Magnetism in Polycrystalline Cobalt-Substituted Zinc Oxide," Physical Review B, Vol. 68, No. 20, 2003, pp. 205202-205209. doi:10.1103/PhysRevB.68.205202

[9] C. N. R. Rao and F. L. Deepak, "Absence of Ferromagnetism in Mn- and Co-doped ZnO," Journal of Materials Chemistry, Vol. 15, No. 5, 2005, pp. 573-578. doi:10.1039/b412993h

[10] S. Thota, T. Dutta and J. Kumar, "On the Sol-Gel Synthesis and Thermal, Structural, and Magnetic Studies of Transition Metal(Ni, Co, Mn) Containing ZnO Powders,"
Journal of Physics: Condensed Matter, Vol. 18, No. 8, 2006, pp. 2473-2478. doi:10.1088/0953-8984/18/8/012

[11] K. Ueda, H. Tabata and T. Kawai, "Magnetic and Electric Properties of Transition-Metal-Doped ZnO Films," Applied Physics Letters, Vol. 79, No. 7, 2001, pp. 988-990. doi:10.1063/1.1384478

[12] B. K. Roberts, A. B. Pakhomov, V. S. Shutthanandan and K. M. Krishnan, "Ferromagnetic Cr-Doped $\mathrm{ZnO}$ for Spin Electronics via Magnetron Sputtering," Journal of Applied Physics, Vol. 97, No. 10, 2005, Article ID: 10D3103. doi:10.1063/1.1847914

[13] Z. Jin, T. Fukumura, M. Kawasaki, K. Ando, H. Saito, T. Sekiguchi, Y. Z. Yoo, M. Murakami, Y. Matsumoto, T. Hasegawa and H. Koinuma, "High through Put Fabrication of Transition-Metal-Doped Epitaxial ZnO Thin Films: A Series of Oxide-Diluted Magnetic Semiconductors and Their Properties," Applied Physics Letters, Vol. 78, No. 24, 2001, pp. 3824-3826. doi:10.1063/1.1377856

[14] H. J. Lee, S. Y. Jeong, J. Y. Hwang and C. R. Cho, "Ferromagnetism in Li Co-Doped ZnO:Cr," Europhysics Letters, Vol. 64, No. 6, 2003, pp. 797-802. doi:10.1209/epl/i2003-00628-6

[15] S. Kurian, S. Sebastian, J. Mathew and K. C. George, "Structural and Electrical Properties of Nano-Sized Magnesium Aluminate," Indian Journal of Pure and Applied Physics, Vol. 42, No. 12, 2004, pp. 926-933.

[16] B. S. Rema Devi, R. Raveendran and A. V. Vaidyan, "Synthesis and Characterization of $\mathrm{Mn}^{2+}$-Doped $\mathrm{ZnS}$ Nanoparticles," Pramana, Vol. 68, No. 4, 2007, pp. 679-687.

[17] S. Maensiri, P. Laokul and V. Promarak, "Synthesis and Optical Properties of Nanocrystalline ZnO Powders by a Simple Method Using Zinc Acetate Dihydrate and Poly (Vinyl Pyrrolidone)," Journal of Crystal Growth, Vol. 289, No. 1, 2006, pp. 102-106. doi:10.1016/j.jcrysgro.2005.10.145

[18] S. Suwanboon, "Structural and Optical Properties of Nanocrystalline $\mathrm{ZnO}$ Powder from Sol-Gel Method," Science Asia, Vol. 34, No. 1, 2008, pp. 31-34. doi:10.2306/scienceasia1513-1874.2008.34.031

[19] B. N. Dole, V. D. Mote, V. R. Huse, Y. Purushotham, M. K. Lande, K. M. Jadhav and S. S. Shah, "Structural Studies of Mn Doped ZnO Nanoparticles," Current Applied Physics, Vol. 11, No. 3, 2011, pp. 762-766. doi:10.1016/j.cap.2010.11.050 